Bio - grafia. Escritos sobre la Biología y su Enseñanza. ISSN 2027

Edición Extraordinaria. p.p. 399 - 411

Memorias del VIII Encuentro Nacional de Experiencias en Enseñanza de la Biología y la Educación Ambiental. III Congreso Nacional de Investigación en Enseñanza de la Biología.

\title{
ENTRE VERSOS, NARRATIVAS E SABERES: DIÁLOGOS DA LITERATURA DE CORDEL COM A EDUCAÇÃO AMBIENTAL
}

\begin{abstract}
AMONG VERSES, NARRATIVES AND KNOWLEDGES: DIALOGUE BETWEEN CORDEL LITERATURE AND ENVIRONMENTAL EDUCATION
\end{abstract}

\author{
Severo, Thiago Emmanuel Araújo ${ }^{1}$, Araújo, Patrícia Cristina de Aragão ${ }^{2}$
}

\section{Resumo}

A partir do desafio complexo posto por uma educação ambiental que perpassa as diferentes expressões culturais, comunicativas e midiáticas, questões concernentes ao ambiente emergem atualmente nas instâncias científicas, artísticas e culturais. Há, hoje, a necessidade de conhecer e apoiar novas formas de apropriação das práticas sociais de leitura e escrita para a construção de uma educação significativa, que tenha pressupostos de uma educação planetária, que entenda e pratique a diversidade e riqueza não apenas biológica mas, também, cultural. A partir dessa perspectiva propomos nesse artigo eixos de reflexão sobre a aproximação do dialogo ambiental, cientifico e cultural, tomando como núcleo a tradicional literatura de cordel, do nordeste brasileiro. Discutir o valor e dos saberes tradicionais para a educação ambiental e para a vida de educadores e aprendizes pode catalisar as potencialidades educativas necessárias para a (re)significação de uma educação ambiental que dialoga saberes e vivências para além dos moldes das ciências formais, nutrindo novos espaços e significados.

Palavras-chave: educação ambiental, literatura de cordel, ensino de ciências.

\footnotetext{
${ }^{1}$ Universidade Federal do Rio Grande do Norte (UFRN) - Brasil. Departamento de Práticas Educacionais e Currículo - DPEC. E-mail: thiagosev@gmail.com
}

${ }^{2}$ Universidade Estadualda Paraíba (UEPB) - Brasil. Departamento de História. E-mail: 
Bio - grafia. Escritos sobre la Biología y su Enseñanza. ISSN 2027

Edición Extraordinaria. p.p. 399 - 411

Memorias del VIII Encuentro Nacional de Experiencias en Enseñanza de la Biología y la Educación Ambiental. III Congreso Nacional de Investigación en Enseñanza de la Biología.

\begin{abstract}
The complex challenge of an environmental education that permeates different cultural expressions, communication and media issues concerning the environment are now emerging in the scientific, artistic and cultural circles. There is, today, a need of knowledge, practices and support on new ways of appropriation in the social practices of reading and writing towards the construction of a meaningful education. This process assumes, today, a global interface, which understands and practices the diversity and richness not only biologically, but also culturally. From this point of view, we propose in this paper some axis of reflection on the approach of environmental, scientific and cultural dialogue, taking as core the Brazilian's traditional northwestern Cordel literature. We discuss that there is a value in traditional knowledge for environmental education and into the lives of educators and learners, and it can catalyze the educational potential necessary for the significance of an environmental education that dialogues knowledge and experiences beyond the mold of formal sciences, nurturing new spaces and meanings.
\end{abstract}

Key-Words: environmental education, Cordel literature, Science education.

\title{
Introdução
}

A educação em seus vários espaços formais e não formais vem questionando antigos paradigmas que nos impulsionam a refletir enquanto educadores e aprendizes. Estamos em direção à necrose de proposições e práticas pedagógicas pautadas na unilateralidade e na fragmentação das ciências $e$ dos saberes. Pouco a pouco percebemos as rupturas $e$ descontinuidades, orientado pela complexidade das relações socioculturais e ambientais (Almeida, 2009; Morin, 2000). A partir destas descontinuidades a práxis educacional se transforma, abrindo espaço para as meta-relações que nutrem a criação e a ebulição do novo de volta aos diferentes espaços educacionais.

Caminhamos de encontro a uma educação que não se prende à transmissão de conceitos ou de conteúdos, mas se preocupa com a configuração de significados através da compreensão dos diferentes contextos construídos pelos próprios sujeitos em interação. É a partir 
Bio - grafia. Escritos sobre la Biología y su Enseñanza. ISSN 2027

Edición Extraordinaria. p.p. 399 - 411

Memorias del VIII Encuentro Nacional de Experiencias en Enseñanza de la Biología y la Educación Ambiental. III Congreso Nacional de Investigación en Enseñanza de la Biología.

destas relações interculturais (Fleuri, 2004) e complexas entre diferentes subjetividades sociais e culturais que os novos horizontes educativos se configuram.

Dificilmente conseguiremos refletir sobre as problemáticas que versam a práxis docente a partir de um único ponto de vista uma vez que, por ser simplificador, torna-se regulador e hierárquico. Precisamos, por outro lado, estar atentos às múltiplas percepções que se configuram a partir de uma ecologia das ideias, dando suporte as diferentes expressões da cultura (Almeida, 2006a), onde olhar o outro em sua alteridade, identificar as suas diferenças e contextualizá-las, ao invés de julgá-las, sejam as principais metas elegidas por esta educação de base complexa.

O nosso objetivo nesse artigo é esgarçar possibilidades dialógicas entre o cultural e o natural, entre a educação ambiental e o conhecimento popular, no sentido de privilegiar a diversidades. Em um primeiro momento, no entanto, é necessário circunscrever os pontos de encontro entre esses eixos do pensamento.

\section{Sobre a emergência de uma nova educação ambiental}

Precisamos estar aptos a escutar o silencio trazido pelos paradigmas emergentes, em meio a tantos ruídos e interferências, a fim de religar homem, natureza e sociedade, em suas diversas ordens: objetivas, subjetivas, individuais e noológicas, como explica Morin et al.(2009). Dentre várias interferências, os autores nos convidam a lançar olhares sobre aquelas trazidas pela globalização econômica nos espaços escolares, como a hegemonização de culturas, por fragmentarem a compreensão complexa de um meio ambiente que seja construído e significado através das relações sociais e culturais.

Segundo os autores, em primeiro lugar, a educação precisa estar fundada sobre aspectos planetários que expressem a inserção simbiótica, mas, ao mesmo tempo, estranha da humanidade no planeta terra, e não na perspectiva globalizadora pautada em inteligências fracionadas, uma vez que esta limita o livre olhar e separa ao invés de unir, destruindo todas as possibilidades de reflexão e compreensão sobre um todo complexo $e$ multidimensional. 
Bio - grafia. Escritos sobre la Biología y su Enseñanza. ISSN 2027

Edición Extraordinaria. p.p. 399 - 411

Memorias del VIII Encuentro Nacional de Experiencias en Enseñanza de la Biología y la Educación Ambiental. III Congreso Nacional de Investigación en Enseñanza de la Biología.

No mundo globalizado, "sentir-se parte" de algo, a partir do que se é em essência, é um sentimento escasso, até mesmo na esfera local. De acordo com Almeida (2006b), este sufocamento é favorecido, principalmente, pela separação entre a cultura científica e a cultura humanística e pela hegemonia da primeira sobre a segunda. Fleuri (2004) nos explica que estas rupturas estão relacionadas a uma crescente globalização da economia e das tecnologias da comunicação que, em sua maioria, são pautadas em valores de dominação, sufocando as diferentes vozes que compõem a nossa sociedade.

Nosso papel enquanto educadores e aprendizes perpassa todas estas questões, portanto, precisamos estar atentos não só aos conhecimentos e culturas oficiais, legitimadas pelas instituições, mas também àqueles paralelos, os conhecimentos tradicionais, as narrativas e oralidades. Assim, poderemos estabelecer diálogos mais ricos e justos, a fim de diminuir binarismos presentes entre sociedade e meio ambiente, homem e natureza, nos espaços escolares. Como nos diz Almeida (2008),

se estamos no coração do sistema educacional - seja como alunos, seja como professores - é desse lugar que devemos refletir sobre como aprender e educar para a complexidade do mundo e para a incerteza, que é a marca do nosso tempo. Nossa tarefa é, pois, intransferivel. [...] Cabe-nos avaliar como as instituições educacionais têm desempenhado sua missão de educar o cidadão para a vida (Almeida, 2008, p. 135).

Quando aproximamos estas reflexões das ideias trazidas por Freire, percebemos que uma educação que se preocupe com as questões planetárias, de pertencimento e de atividade pela práxis, se distancia da educação ambiental tradicional, pautada apenas em discursos de falsa atividade. Estas perspectivas retrógradas são munidas de modelos prontos e práticas redundantes, evidenciando mais ainda as dicotomias entre homem e natureza. Estes tipos de abordagem não são significativas para a vida de alunos e alunas por não permitirem diálogos com os diferentes conhecimentos, culturas e saberes. 
Bio - grafia. Escritos sobre la Biología y su Enseñanza. ISSN 2027

Edición Extraordinaria. p.p. 399 - 411

Memorias del VIII Encuentro Nacional de Experiencias en Enseñanza de la Biología y la Educación Ambiental. III Congreso Nacional de Investigación en Enseñanza de la Biología.

As relações de ensino e aprendizagem precisam estar pautadas na perspectiva de inacabamento de homens e mulheres, e esta característica "exige que o processo educativo escolar esteja permanentemente aberto as questões emergentes na sociedade" (Freire, 1997, p. 16).

Deste modo, torna-se importante percebermos a educação ambiental a partir da complexidade do nosso tempo, ou seja, como um ato comunicativo e significativo, em sintonia com as expectativas das pessoas e com os verdadeiros problemas ambientais que emergem nas esferas políticas, sociais e culturais, não como um conjunto de práticas herméticas. A partir deste ponto de vista, esta proposta educacional sugere mais do que um diálogo entre aspectos técnicos ou conceituais sobre um ambiente distante da realidade de homens e mulheres. Por outro lado, defende uma situação de envolvimento e, acima de tudo, de (des)encontros formativos que perpassam a ética e a justiça entre os indivíduos, suas relações socioculturais e o meio ambiente (Reigota, 1999, p. 82).

Pautados na incerteza de nosso tempo e na ecologia das ideias que estas novas práticas trazem ao contexto educacional, propomos um diálogo pautado na diferença e no pertencimento às questões ambientais, um diálogo entre natureza e cultura, em suas diferentes expressões. Nessa ótica complexa, a cultura torna-se um espaço de compartilhamento de significados, e é a partir deste lugar que aprendemos a nos relacionar com a natureza, e assim "vamos estabelecendo nosso lugar no mundo, ou seja, sabendo quem nós nos tornamos dia a dia" (Guimarães, 2008 p. 88). Portanto, "nada melhor para 0 trabalho com a educação ambiental que aceitar o desafio de ensinarmos/aprendermos em parceria, valorizando, radicalmente, nossas experiências, subjetividades, histórias, trajetórias e individualidades" (Barcelos, 2010, p. 26).

No que se refere à prática pedagógica na escola em seus diversos âmbitos, e sua (in)existência fora dela, percebemos o desafio que nos é posto como educadores e aprendizes através da educação ambiental. É necessário perceber a sensibilidade do possivel para ir além dos métodos e contextualizar os temas abordados rumo a uma práxis social. Neste sentido, a educação ambiental deixa de se configurar como transversalidade durante o ensino e se torna intrínseco ao processo educativo, que beneficia a construção de 
Bio - grafia. Escritos sobre la Biología y su Enseñanza. ISSN 2027

Edición Extraordinaria. p.p. 399 - 411

Memorias del VIII Encuentro Nacional de Experiencias en Enseñanza de la Biología y la Educación Ambiental. III Congreso Nacional de Investigación en Enseñanza de la Biología.

uma consciência socioambiental e a "necessidade de se enfrentar concomitantemente a degradação ambiental dos problemas sociais." (Bispo \& Oliveira, 2007, p. 1).

Mesmo comprometidos com práticas renovadoras, a perspectiva atual de ensino continua a seguir os moldes oficiais formais, valorizando métodos redundantes e buscando uma constante erudição das especialidades e fragmentação das ciências. De acordo com Almeida (2009), estas são as características de uma ciência tímida intelectualmente que, por ter medo de criar e crer em seus próprios caminhos, se vale de receitas "frankesteinianas" e "obsessões cognitivas" na ordem do "como fazer" e do "como aplicar" (Almeida, 2009, p. 9).

Trata-se não de pensar em retrocessos, mas de recriar posturas a partir dos paradigmas emergentes, das culturas de nosso tempo, dos diferentes contextos educacionais, políticos e ambientais em que vivemos. Trata-se, portanto, de criar um ensino onde possamos "introduzir o sujeito no conhecimento, o observador na realidade" e ao mesmo tempo "religar, sem fundir, ciência, arte, filosofia e espiritualidade" (Almeida, 2009, p.12). É na ênfase destas relações dialéticas que iremos permitir o reconhecimento da complexidade, da polissemia, da fluidez e da relacionalidade dos fenômenos humanos e culturais (Fleuri, 2004).

$\mathrm{Na}$ concepção de Layrargues (2002) a educação ambiental é uma ferramenta capaz de "acelerar o processo de disseminação do pensamento ecológico no tecido social e promover a conversão para uma sociedade sustentável" (Layrargues, 2002, p. 9). E que esta disseminação não seja hegemônica nem hierárquica. Que se destaquem as diferenças, que sobrem as arestas. É a partir deste tecido fértil que a educação ambiental pode ser utilizada como ferramenta para interconectar os conhecimentos de diversas ordens.

Esta é, também, a abordagem prevista pelos Parâmetros Curriculares Nacionais para a educação ambiental: Subsidiar a formação de cidadãos conscientes e ativos, preocupados com a "construção de um mundo socialmente justo e ecologicamente equilibrado, o que requer responsabilidade individual e coletiva em níveis local, nacional e planetário" (MEC/BRASIL, 1999, p.181).

Ao lançar mão de uma educação comprometida com as diferenças e de uma escola fértil, como possível espaço de liberdade e de criação, enxergamos a educação ambiental de 404 
Bio - grafia. Escritos sobre la Biología y su Enseñanza. ISSN 2027

Edición Extraordinaria. p.p. 399 - 411

Memorias del VIII Encuentro Nacional de Experiencias en Enseñanza de la Biología y la Educación Ambiental. III Congreso Nacional de Investigación en Enseñanza de la Biología.

maneira mediada e investigativa, caminhando em direção da compreensão da "realidade como construção social mobilizada por valores, interesses e utopias".

Nesse sentido, a articulação com o diverso no sentido de atribuir riqueza a percepção de ambiente e de mundo se faz presente na reflexão da próxima sessão do artigo, onde tomamos como modelo cognitivo a literatura de Cordel, tradicional do nordeste do Brasil, para demonstrar eixos de possibilidades de diálogo entre cultural e natural, cientifico e tradicional, arte e ciência.

Por entre os versos do folheto de cordel: diálogo com a educação ambiental

Na Literatura de Cordel ou Folhetos de Cordel, como são conhecidos, os poetas populares resgatam e se reinventam, mergulhando em sua subjetividade para representar o que percebem e o que vivem. Através do lúdico, estas narrativas surgem e se transformam do real para o imaginário, e vice-versa. Na região Nordeste, onde são amplamente confeccionados, servem tanto como entretenimento, quanto como artefato comunicativo $e$ educativo, pois através destes são divulgados registro e acontecimentos históricos atuais, além de conflitos, pensamentos ou, até mesmo, receitas de medicina alternativa (F. I. C. d. Silva \& Souza, 2006).

É através dos contos e dos causos narrados nestas publicações que o "poeta popular revela e condensa, na sua pureza, a expressão legítima de uma realidade social" (Lopes, 1983, p. 8) partindo de uma visão própria e transformando-a de forma lúdica em versos. Esta forma descontraída e ritmada é peculiaridade dessa vertente literária, que, na construção desses textos, contempla sua percepção dos acontecimentos. Na confecção dos folhetos, a construção dos versos é feita a partir de vocabulário e significados regionais, trabalhadas a partir dos conhecimentos adquiridos pelo escritor no seu cotidiano e na sua interpretação do mundo vivido (F. I. C. d. Silva \& Souza, 2006).

De acordo com os registros, a literatura de cordel tem seus antecedentes na França medieval. Possui um itinerário amplo antes de chegar às terras brasileiras, passando por Portugal, com sua chegada ao Brasil por volta dos séculos XVI e XVII (Porfiro, 1999). Apesar de não ter surgido nesta região, foi no Nordeste que o cordel passou a florescer. 
Bio - grafia. Escritos sobre la Biología y su Enseñanza. ISSN 2027

Edición Extraordinaria. p.p. 399 - 411

Memorias del VIII Encuentro Nacional de Experiencias en Enseñanza de la Biología y la Educación Ambiental. III Congreso Nacional de Investigación en Enseñanza de la Biología.

Em seu estudo sobre a cultura dos folhetos de cordel, Araújo (2007) nos explica que esta relação com a região nordeste se deve ao hábito secular de contar história que o povo desta região traz consigo. E esta relação estabelecida entre os contadores de histórias e os cantadores das rimas de cordel construiu-se intimamente "não só porque o público de ambos é o mesmo, mas também porque a maioria das histórias contadas e cantadas em versos advém das classes populares" (Araújo, 2007, p. 47).

Esta facilidade de construção próxima ao lúdico e ao popular faz do cordel um estilo de compreender e construir pontos de vista sobre o mundo, as coisas e as relações, como nos lembra Gonçalves (2007). "O cordel evoca, por assim dizer, uma cosmologia por meio de seu verso" (Gonçalves, 2007, p. 23). Estas características fazem do cordel um importante artefato educativo e comunicativo, que não vê distinção entre classes sociais, abrindo espaço para potencializar as inquietações e subjetividades de anônimos em versos e rimas, valorizando saberes e experiências.

Neste sentido, como posto por Araújo (2007), a cultura popular expressa pela literatura de cordel constitui-se de um saber-fazer provido a partir das vivências dos poetas e dos diálogos com diversos saberes e culturas, que permite trocas de experiências e significados vivenciadas no coletivo e no individual. Esta proximidade com o outro, com o lúdico tem fascinado e envolvido jovens e adultos que, ao lerem e ouvirem os cordéis, cantam junto com o poeta, "despertando o interesse e fugindo aos padrões gramaticais convencionais" (Araújo, 2007, p. 51).

A literatura de cordel é considerada um dos campos dos estudos literários mais férteis e fascinantes, não só devido à vitalidade de sua produção, mas, sobretudo, à maneira como tem enfatizado aspectos relativos à vida cotidiana e aos acontecimentos que fazem parte da sociedade brasileira (Araújo, 2007, p. 51). 
Bio - grafia. Escritos sobre la Biología y su Enseñanza. ISSN 2027

Edición Extraordinaria. p.p. 399 - 411

Memorias del VIII Encuentro Nacional de Experiencias en Enseñanza de la Biología y la Educación Ambiental. III Congreso Nacional de Investigación en Enseñanza de la Biología.

O cordel, mais de que um "estilo" literário, perpassa as expressões culturais e se traduz em diversas possibilidades educativas e comunicativas. As potencialidades destes artefatos tornam-se ainda mais significativas quando vistas à luz dos paradigmas atuais da educação ambiental. De acordo com Araújo (2007), o cordel como elemento educativo nesta perspectiva intercultural e complexa resulta na construção de aprendizagens múltiplas, fruto das experiências sociais adquiridas na coletividade. Procuramos novos espaços e rupturas ao aproximar ciências e artes, onde as relações e diálogos floresçam em meio a substratos complexos. Portanto, a utilização da literatura para dialogar diferentes saberes e culturas torna-se muito importante podendo "também conduzir à interdisciplinaridade e à formulação de projetos educacionais que são essenciais para a inserção da educação ambiental" (Zanon, 2006, p. 61) e planetária nos espaços escolares.

Ao longo de uma rica discussão sobre as interfaces educativas na educação ambiental $e$ seus possíveis diálogos com a arte e a literatura, Silva (2009) nos faz refletir sobre este rico diálogo para a construção de uma educação política e justa. Para o autor, esta educação perpassa os temas curriculares de Biologia, Ecologia e outras ciências, ampliando-se para a "participação dos cidadãos na busca de uma sociedade justa, participativa e equitativa" ( $A$. A. d. Silva, 2009, p. 35). Esta condição política não é apenas uma mediação de ordem técnica, mas é a partir dela que:

educação ambiental é vista como espaço para que se construam diálogos entre a poesia e as ciências, de modo a direcionar o homem e mulher à edificação de uma ciência não só pela técnica, mas pela ética e estética, na razão dialógica, na alteridade, com vistas à construção de outras formas de saberes e práticas (A. A. d. Silva, 2009, p. 10).

Ao pensarmos nas possibilidades e potencialidades desta Educação Ambiental, articulada com os fenômenos expressos pelas relações culturais e dialogando com a literatura de cordel e os saberes por ela trabalhados, nos deparamos com inúmeros diálogos acerca destas temáticas. Quando postas as diferenças do outro, do estranho, ou quando nos 407 
Bio - grafia. Escritos sobre la Biología y su Enseñanza. ISSN 2027

Edición Extraordinaria. p.p. 399 - 411

Memorias del VIII Encuentro Nacional de Experiencias en Enseñanza de la Biología y la Educación Ambiental. III Congreso Nacional de Investigación en Enseñanza de la Biología.

aproximamos de outras práticas pedagógicas, proporcionamos, também, estranhamentos e conflitos. É nesta relação (in)tensa e conflituosa que ocorrem as trocas e (re)significações culturais e, até mesmo, o surgimento de novas. Neste sentido, Bhabha (2003) nos lembra que é esta relação fronteiriça entre as culturas que alimenta e nutre o "novo", criado e transformado através destes entre-lugares, tão necessários à formação humana nos espaços escolares, e fora deles.

A partir destes entre-lugares complexos de diálogo intercultural, a criação e frutificação de novas abordagens tornam-se possiveis. Contudo, de acordo com Farias (2006, p. 21), a exclusão ou negação destes espaços e saberes não-científicos na sala de aula "mascara o campo de tensão tão fundamental para a espécie humana, inscrita nas diversas interpretações sobre um mesmo fenômeno", Ihes roubando qualidade e riqueza. $O$ autor alerta que esta ausência de saberes não-científicos na sala de aula acaba gerando verdades unitárias, já que tem como ponto de referência apenas o conteúdo transmitido pelo conhecimento escolar, fomentando nos jovens e adultos o sentimento de intolerância contra qualquer coisa que não thes seja familiar.

\section{Diversidade de Naturezas e Culturas}

Nos aproximamos dos possíveis diálogos a partir da literatura de cordel e da educação ambiental na intenção de ressaltar a importância das mediações culturais e pedagógicas que estes artefatos educativos asseguram, visto que trazem consigo uma "polifonia de dizeres sobre o mundo", favorecendo "um pensamento complexo que encoraja a ação e reconhece a incerteza" (Farias, 2006, p. 22).

É a partir deste desafio complexo de uma educação ambiental que perpassa as diferentes expressões culturais, comunicativas e midiáticas, que percebemos como as questões concernentes ao ambiente emergem atualmente nas instâncias científicas, artísticas, subjetivas e culturais, assim como a necessidade de conhecer e apoiar novas formas de apropriação das práticas sociais de leitura e escrita para a construção de uma educação significativa, que tenha pressupostos de uma educação planetária. 
Bio - grafia. Escritos sobre la Biología y su Enseñanza. ISSN 2027

Edición Extraordinaria. p.p. 399 - 411

Memorias del VIII Encuentro Nacional de Experiencias en Enseñanza de la Biología y la Educación Ambiental. III Congreso Nacional de Investigación en Enseñanza de la Biología.

A partir desta perspectiva, torna-se imperativo discutir o valor e dos saberes tradicionais para a educação ambiental e para a vida de educadores e aprendizes. Implicados pela literatura de cordel e sua expressão enquanto saber tradicional, acreditamos que esse gênero literário e musical pode constituir-se como fios condutores entre as narrativas, os saberes da tradição e os saberes científicos, catalisando suas potencialidades educativas necessárias para a (re)significação de uma educação ambiental planetária de bases complexas.

Tomando como foco este banquete de saberes e de vivências que vão além dos moldes das ciências formais, acreditamos que o diálogo com o olhar que o poeta cordelista lança sobre si, sobre sua arte e sobre a natureza, através de suas narrativas e dos versos presentes nos folhetos de cordel, podem nutrir novos espaços, saberes e significados.

\section{Referências Bibliográficas}

Almeida, M. d. C. d. (2006a). Narrativas de uma ciência da inteireza. In E. C. d. Souza (Ed.), Autobiografias, histórias de vida e formação: pesquisa e ensino: Porto Alegre: EDIPUCRS; Salvador: EDUNEB.

Almeida, M. d. C. d. (2006b). Prefácio - Um alpendre lilás para a educação. In C. A. Farias (Ed.), Alfabetos da Alma - Histórias da tradição na escola. Porto Alegre: Sulina.

Almeida, M. d. C. d. (2008). Complexidade e Ecologia das Ideias. In C. Almeida \& I. Petraglia (Eds.), Estudos de Complexidade 2. São Paulo: Xamã.

Almeida, M. d. C. d. (2009). Complejidad y el Vuelo Incierto de La Mariposa. Visión Docente Con-Ciencia(47), 5-19.

Araújo, P. C. d. A. (2007). A CULTURA DOS CORDÉIS: território(s) de tessitura de saberes. (Doutorado), Universidade Federal da Paraíba, João Pessoa, PB.

Barcelos, V. (2010). Antropofagia, Educação Ambiental e Intercultura - tecendo uma nãopedagogia. In L. B. Guimarães, A. G. Krelling \& V. Barcelos (Eds.), Tecendo Educação Ambiental na arena cultural (pp. 11-31). Petrópolis, RJ: DP et Alli.

Bhabha, H. K. (2003). O local da cultura (M. Ávila, E. L. d. Lima \& G. R. Gonçalves, Trans.). Belo Horizonte: Editora UFMG.

Bispo, M. O., \& Oliveira, S. F. (2007). Diferentes olhares sobre meio ambiente e educação ambiental: as representações dos professores de Cristalândia- To. Revista Eletrônica do Mestrado em Educação Ambiental, 18, 399-414. 
Bio - grafia. Escritos sobre la Biología y su Enseñanza. ISSN 2027

Edición Extraordinaria. p.p. 399 - 411

Memorias del VIII Encuentro Nacional de Experiencias en Enseñanza de la Biología y la Educación Ambiental. III Congreso Nacional de Investigación en Enseñanza de la Biología.

Farias, C. A. (2006). Alfabetos da Alma - Histórias da tradição na escola. Porto Alegre: Sulina.

Fleuri, R. M. (2004). Intercultura e Educação. Paper presented at the $O$ desafio dialógico nas relações interculturals - VI Encontro Internacional do Fórum Paulo Freire, Porto, Portugal.

Freire, P. (1997). Pedagogia da Autonomia: saberes necessários à prática educativa. São Paulo: Paz e Terra.

Gonçalves, M. A. (2007). Cordel Híbrido, Contemporâneo e Cosmopolita. Textos escolhidos de cultura e arte populares, Rio de Janeiro, 4, 21-38.

Guimarães, L. B. (2008). A Importância da História e da Cultura nas Leituras da Natureza. Inter-ação (Goiânia), 33, 89-112.

Layrargues, P. P. (2002). Muito prazer, sou a educação ambiental, seu novo objeto de estudo sociológico. Paper presented at the I Encontro da Associação Nacional de Pós Graduação e Pesquisa em Ambiente e Sociedade, Indaiatuba.

Lopes, R. (1983). Literatura de cordel: antologia. Fortaleza, CE: BNB.

MEC/BRASIL. (1999). Parâmetros Curriculares Nacionais, Ciências da Natureza, Matemática e suas Tecnologias. Brasília: MEC/SEF.

Morin, E. (2000). Da necessidade de um pensamento complexo. In F. Menezes \& J. M. d. Silva (Eds.), Para nevegar no século XXI. Porto Alegre: Sulina; Edipucrs.

Morin, E., Ciurana, E.-R., \& Motta, R. D. (2009). Educar na era planetária: o pensamento complexo como método de aprendizagem no erro e na incerteza humana. São Paulo: Cortez, Brasília - DF : UNESCO.

Porfiro, J. C. M. (1999). Literatura de Cordel, Educação e Formação da Consciência Crítica. (Doutorado), Universidade Estadual de Campinas, Campinas.

Reigota, M. (1999). A Floresta e a Escola: por uma educação ambiental pós-moderna. São Paulo: Cortez.

Silva, A. A. d. (2009). Ciência e Poesia em diálogo: uma contribuição à educação ambiental. (Mestrado), Universidade de Sorocaba, Sorocaba.

Silva, F. I. C. d., \& Souza, E. D. d. (2006). INFORMAÇÃO E FORMAÇÃO DA IDENTIDADE CULTURAL: o acesso à informação na literatura de cordel. Informação \& Sociedade: Estudos, 16, 215-222.

Zanon, A. M. (2006). A utilização de obras literárias no ensino e no exercício da educação ambiental. In I. A. d. Vargas, S. Wiziack, V. d. M. Machado \& Y. Medeiros (Eds.), 
Bio - grafia. Escritos sobre la Biología y su Enseñanza. ISSN 2027

Edición Extraordinaria. p.p. 399 - 411

Memorias del VIII Encuentro Nacional de Experiencias en Enseñanza de la Biología y la Educación Ambiental. III Congreso Nacional de Investigación en Enseñanza de la Biología.

Educação Ambiental: gotas de saber: reflexão e prática. Campo Grande: Editora Oeste. 